\title{
O PROCESSO DE FORMULAÇÃO DO PLANO MUNICIPAL DE EDUCAÇÃO DE DOURADOS-MS
}

\author{
THE PROCESS OF FORMULATION OF THE MUNICIPAL PLAN OF \\ EDUCATION OF DOURADOS-MS
}

\begin{abstract}
Flávia Paula Nogueira ARANDA ${ }^{1}$
Fábio PERBONI ${ }^{2}$

Resumo: Esse artigo apresenta o processo de formulação do Plano Municipal de Educação (PME) do município de Dourados, Mato Grosso do Sul. Teve como objetivo analisar como se deu o processo de elaboração do PME; bem como os embates vivenciados durante o processo de formulação do documento. Essa pesquisa é parte do resultado de uma Dissertação de Mestrado, da Linha de Pesquisa "Política e Gestão da Educação", do Programa de Pós-Graduação em Educação - Mestrado e Doutorado - da Universidade Federal da Grande Dourados (UFGD). A pesquisa está pautada em estudo qualitativo e pesquisa documental, foram consultadas bases de dados preparadas pelo Instituto Brasileiro de Geografia e Estatísticas (IBGE) e Instituto Nacional de Estudos Pedagógicos Anísio Teixeira (INEP). O estudo do tema tem relevância social na medida em que pode oferecer significativas contribuições para a melhoria da qualidade da educação básica de Dourados, tendo como norte as metas e estratégias formuladas no PME.
\end{abstract}

Palavras-Chave: Políticas públicas. Planejamento educacional. Plano Municipal de Educação.

Abstract: This article presents the process of formulating the Municipal Education Plan (PME) of the municipality of Dourados, Mato Grosso do Sul. Its objective was to analyze how the SME elaboration process took place; as well as the conflicts experienced during the process of document formulation. This research is part of the results of a Masters Dissertation, Research Line "Education Policy and Management", Graduate Program in Education - Masters and Doctoral - Federal University of Grande Dourados (UFGD). The research is based on qualitative study and documentary research, databases were prepared by the Brazilian Institute of Geography and Statistics (IBGE) and the National Institute of Pedagogical Studies Anísio Teixeira (INEP). The study of the theme has social relevance insofar as it can offer significant contributions to the improvement of the quality of the basic education of Dourados, having as a goal the goals and strategies formulated in the PME.

Keywords: Public policies. Educational planning. Municipal Plan of Education.

\footnotetext{
${ }^{1}$ Mestre em Educação - Universidade Federal da Grande Dourados UFGD - flaviaaranda@hotmail.com

${ }^{2}$ Docente Universidade Federal da Grande Dourados UFGD - fabioperboni@ufgd.edu.br
} 


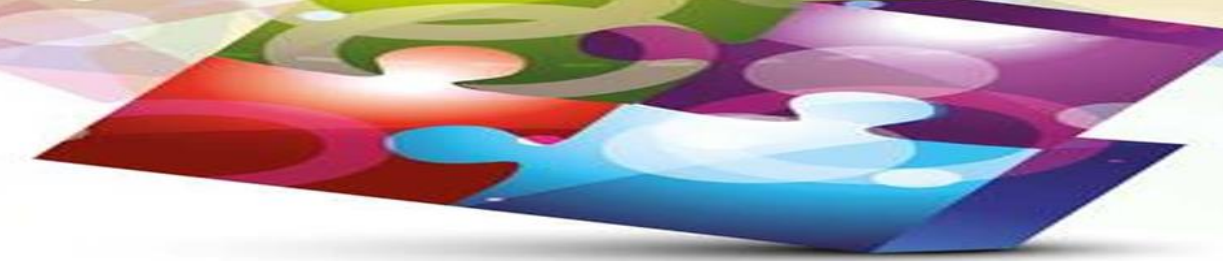

\section{Introdução}

Esse artigo tem como objetivo apresentar uma análise do processo de formulação do Plano Municipal de Educação do município de Dourados-MS; bem como os embates enfrentados durante a elaboração do documento até sua aprovação em 25 de junho de 2015 culminando na Lei N. 3.904 (PME 2015/2025).

Para dar conta de analisar o a elaboração e formulação do PME, apropria-se do ciclo de políticas de Palumbo, considerando que tal documento passa pelas etapas do processo de elaboração de políticas públicas: agenda, formulação, implementação, avaliação e resultados. Porém, a análise se deterá parcialmente ao ciclo de políticas, sendo discutida nesse artigo somente a agenda e a formulação, as demais etapas não serão discutidas nesse trabalho.

Frente ao exposto, justifica-se a abordagem, destacando que:

Porque a política é o resultado de um sistema pra sua formulação, os princípios e as estratégias básicas do governo são desenvolvidos a cada momento do ciclo de uma política, desde o planejamento da agenda até o seu impacto. É útil pensar na elaboração de uma política como um processo seqüencial ou cronológico (PALUMBO, 1994, p.49).

Ainda em aspectos metodológicos, a pesquisa está pautada em estudo qualitativo, que conforme observa Godoy (1995 p.21) "a abordagem qualitativa, não se apresenta como uma proposta rigidamente estruturada, ela permite que a imaginação e a criatividade levem os investigadores a propor trabalhos que explorem novos enfoques".

Trabalhou-se com diversas fontes, como diário oficial, sites de notícias online, site oficial do sindicato local e da prefeitura municipal, artigos, dissertações e teses que tratam do tema, tanto para o levantamento bibliográfico, quanto para o documental.

Cabe destacar que segundo Shiroma, Campos e Garcia (2005, p. 433) na análise documental os textos são considerados como "[...] produto e produtores de orientações políticas no campo da educação", cuja "difusão e promulgação geram também situações de mudanças ou inovações, experienciadas no contexto das práticas educativas".

Para efeito de caracterização geral e educacional do município foram consultadas diferentes bases de dados com destaque para aquelas preparadas pelo 


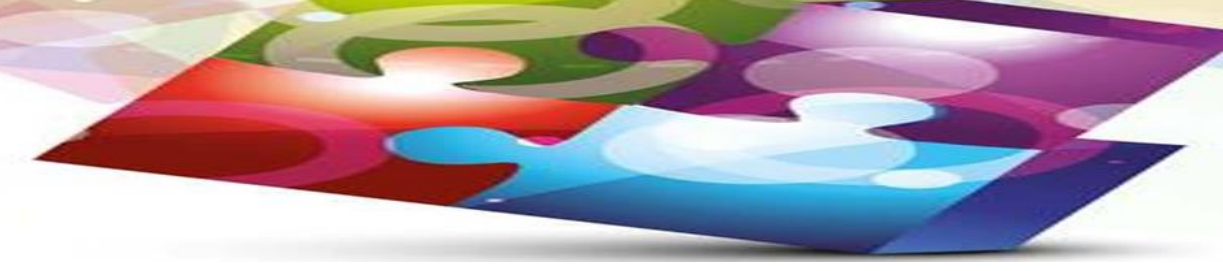

Instituto Brasileiro de Geografia e Estatísticas (IBGE) e pelo Instituto Nacional de Estudos Pedagógicos Anísio Teixeira (INEP). Desenvolvida pesquisa documental por meio de levantamento de fontes primárias e secundárias, como publicações no Diário Oficial e nos Jornais Eletrônicos do município em análise, entre outros documentos identificados no decorrer da pesquisa.

O município de Dourados se localiza a sudoeste do Estado de Mato Grosso do Sul (MS), está a $224 \mathrm{~km}$ de distância da capital Campo Grande, e a $100 \mathrm{~km}$ da fronteira com o Paraguai. Destaca-se como a segunda maior cidade do Estado, possui atualmente, aproximadamente 215.486 mil habitantes (IBGE, 2016). Situado na região CentroOeste, próximo à divisa com o estado do Paraná. Dourados tem como fonte de renda agricultura, pecuária, comércio local e prestação de serviços.

No aspecto educacional, Dourados se propôs a elaborar um plano de educação a partir da aprovação da Lei n. ${ }^{\circ} 13.005$ que dispõe sobre o Plano Nacional de Educação (PNE 2014-2024) que traz em seu artigo 8. ${ }^{\circ}$ a obrigatoriedade de estados e municípios elaborar seus respectivos planos de educação.

O plano de educação se constitui como um documento norteador das políticas públicas que regem a educação municipal de Dourados na atualidade. Portanto, o principal aporte legal na garantia de uma educação que contemple de fato, a formação plena do cidadão, o direito à uma educação de qualidade e a valorização dos profissionais da educação, conforme almejado nas metas e estratégias do PME.

\section{A Lei N. 3.904 de 23 de Junho de 2015: o PME de Dourados-MS}

O momento em que a construção de um planejamento educacional em âmbito municipal esteve presente nos diálogos da administração pública do município deu-se logo após a aprovação da Lei N. ${ }^{0} 13.005$ (PNE/2014-2024) atendendo à demanda explícita na redação no art. $8 .^{\circ}$ da Lei

Art. 8o Os Estados, o Distrito Federal e os Municípios deverão elaborar seus correspondentes planos de educação, ou adequar os planos já aprovados em lei, em consonância com as diretrizes, metas e estratégias previstas neste PNE, no prazo de 1 (um) ano contado da publicação desta Lei (BRASIL, 2014). 


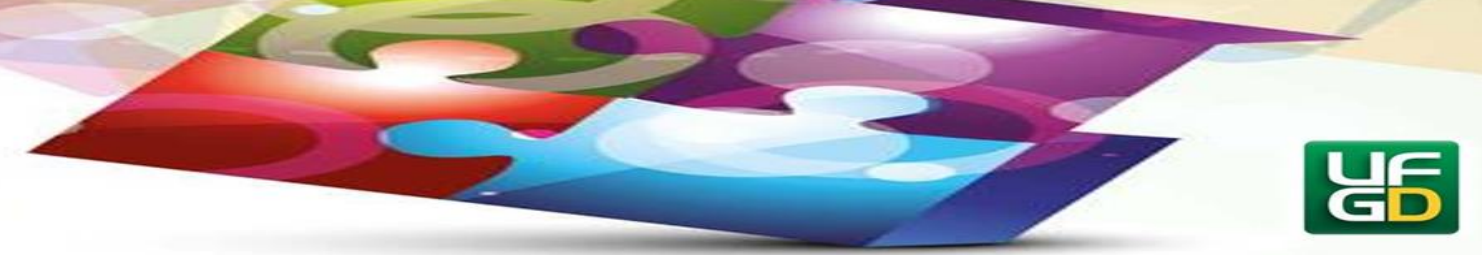

Cabe ressaltar que PNE 2014-2024 é composto por 14 Artigos, 20 Metas e 254 Estratégias. De início, apresenta-se uma súmula do Plano, numa demonstração das ideias básicas que o sustentam, as quais o PME de Dourados se baseia.

Figura 1 - Metas do PNE (2014-2024)

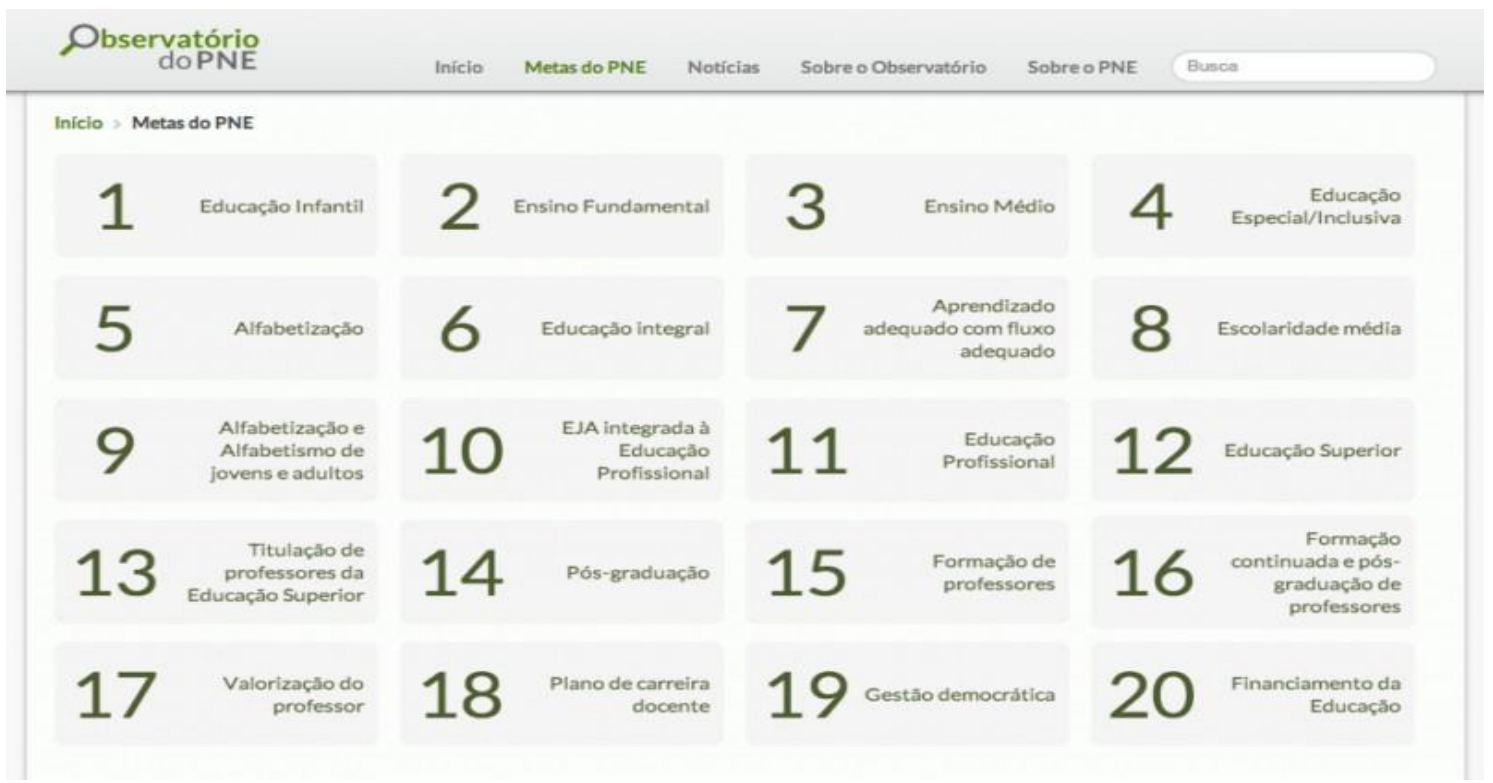

Fonte: Observatório do PNE - Disponível em: http://www.observatoriodopne.org.br/metas-pne

No dia 24 de Abril de 2014 foi publicado no Diário Oficial n. ${ }^{\circ} 3.712$ por meio da Resolução N. ${ }^{0}$ 21/2014, a Comissão para a elaboração e criação do Plano Municipal de Educação (PME) com nomes de representantes da sociedade civil e da Secretaria Municipal de Educação (SEMED) do município de Dourados.

Diante da lei estabelecer um prazo para que o documento fosse elaborado, o município de Dourados deu início à organização no dia 15 de Abril de 2014 com a primeira reunião que teve como pauta assuntos pertinentes acerca da elaboração do PME, como: organização do calendário, elaboração do regimento interno, plano de ação de trabalho, dentre outros (DOURADOS, 2015).

Em consonância com as orientações do MEC, por meio do caderno de orientações para elaboração dos PME's, a SEMED nomeia como coordenadora da elaboração do PME de Dourados, a Assessora Pedagógica do Núcleo de Educação Infantil 


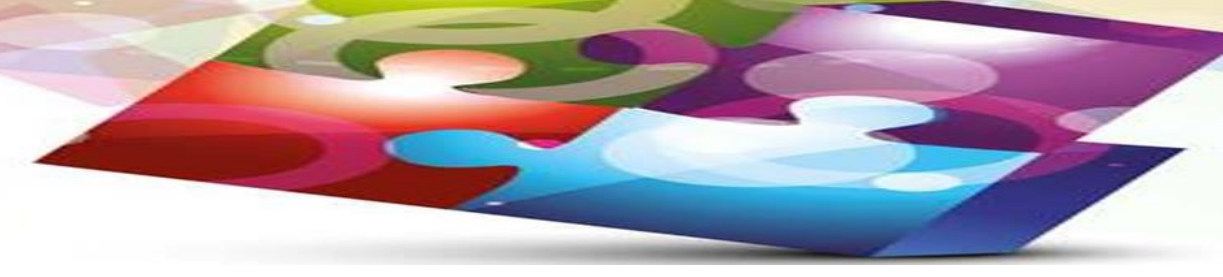

Considerando o caráter técnico do trabalho, o grupo pode ser composto por pessoas das equipes da Secretaria de Educação, Administração, Planejamento e Finanças do Município e, se for possível, também por representantes técnicos da Secretaria de Estado de Educação. O importante é que todos compreendam que o produto dessa equipe deve ser oferecido à Comissão para que, depois de validado, transforme-se no Documento-Base que servirá de referência para a divulgação e para o debate mais ampliado (BRASIL, 2014, p.9).

O caderno de orientações do MEC apresenta uma gama de procedimentos indispensáveis a serem considerados pela equipe técnica na elaboração do PME, como por exemplo, alinhamento ano PNE e PEE; que o PME é entendido como um documento da educação municipal como um todo, e não de uma rede de ensino específica; a estimulação da participação ativa da sociedade; a equipe técnica deve ter o conhecimento do cenário local; articulação com os demais instrumentos de planejamento (PPA, PAR, etc);

Segundo informações do texto de apresentação do PME, foram criadas seis subcomissões, as quais escreveram o texto inicial do PME, a partir das vinte metas do PNE. Essas comissões puderam compor os membros de sua equipe para auxiliá-los nas discussões em torno do texto base, propondo alterações, elaborando estratégias e auxiliando na escrita das propostas.

O texto inicial do PME foi apresentado para a comunidade escolar e sociedade civil e seus segmentos no dia 25 de Agosto de 2014, na Câmara Municipal de Dourados, onde se realizou o $1^{\circ}$ Seminário Livre, sobre o PME, organizado pela Secretaria Municipal de Educação (SEMED).

Por meio da mídia local e ferramentas de comunicação, a SEMED convidou todos os educadores e a população em geral a participar do seminário, tendo como objetivo fazer uma explanação sobre o documento e apresentação das 20 metas do Plano Nacional de Educação (PNE), norteadores do documento a ser elaborado. 
Segundo dados coletados no site oficial da Prefeitura Municipal de Dourados, o Plano Municipal de Educação articulado ao Plano Estadual ${ }^{3}$ e Plano Nacional de Educação, possui as mesmas metas, porém, as estratégias são voltadas à realidade do contexto local. Conforme aponta o site, o PME consiste num documento referência para orientar as políticas educacionais nos próximos dez anos, subsidiando as decisões, a execução das ações, criando mecanismos de acompanhamento e avaliação (DOURADOS, 2015).

Foram inúmeras plenárias para elaboração do PME - Dourados, construção de estratégias que contou com a participação de professores, gestores e administrativos das escolas públicas e privadas do município, além de representantes dos órgãos públicos do Conselho Municipal de Educação (COMED) e Conselho Tutelar; representantes das instituições de ensino superior, Universidade Federal da Grande Dourados (UFGD) e Universidade Estadual de Mato Grosso do Sul (UEMS); representantes das modalidades de educação como comunidade indígena, do campo, educação especial, movimento negro, movimento LGBT; ainda, representantes do ministério público, poder legislativo e Sindicato dos Trabalhadores em educação de Dourados (SIMTED) e Sindicato dos Trabalhadores em Educação da Rede Particular de Ensino (SINTRAE-SUL).

A construção da lei buscou a afetiva participação da sociedade civil e seus segmentos, a comunidade escolar estava interessada e comprometida com a formulação do plano, entendendo a importância que tal documento representa para a educação douradense, um marco, pois é a primeira vez que Dourados elabora 20 metas para a educação, contemplando desde a Educação Infantil até o Ensino Superior pelos próximos dez anos.

No mês de Maio de 2015, após 18 meses de discussão em torno do PME, o texto do documento foi finalizado durante o seminário realizado no auditório da Universidade da Grande Dourados (UNIGRAN). A aprovação aconteceu em assembléia reunindo os representantes dos mais diversos segmentos educacionais e civis, o Projeto de Lei n. ${ }^{\circ}$ 14/2015, seguiu os tramites legais, passando pelo executivo e posteriormente

\footnotetext{
${ }^{3}$ O Plano Estadual de Educação de Mato Grosso do Sul (PEE-MS) foi aprovado em 22 de Dezembro de 2014 pela Lei N. 4.621 (2014-2024).
} 


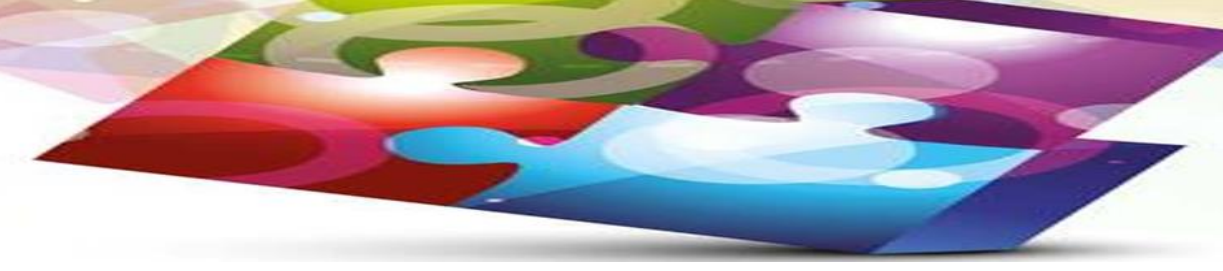

encaminhado à Câmara Municipal para aprovação pelo legislativo, como noticia o site da Câmara Municipal de Dourados.

No entanto, o documento que chegou à Câmara Municipal, não era o mesmo que havia sido aprovado em assembléia, uma vez que o poder executivo "retirou $20 \%$ das propostas aprovadas e modificou $80 \%$ das demais" ${ }^{\prime 4}$, comentou um dos vereadores no momento de discussão do projeto de lei. As alterações foram propostas pelo departamento jurídico da Prefeitura Municipal como informa no site da Câmara Municipal de Dourados.

Todos os itens modificados ou suprimidos do documento foram apresentados como emendas ao Plano Municipal de Educação, pelo vereador Elias Ishy (PT), totalizando mais de 190 (cento e noventa) emendas. Conforme notícia publicada no site do SIMTED

No levantamento realizado pelo gabinete do vereador Elias Ishy (PT) ficou constatado que Prefeitura suprimiu 71 das 376 estratégias elaboradas pelos profissionais da Educação e entidades da sociedade. Além disso, outras tantas foram modificadas, a maioria retirando prazos para o cumprimento de metas e suprimindo itens que são reivindicações antigas dos profissionais de Educação do município [...] (SIMTED, 2015).

As reivindicações foram desconsideradas pelo conjunto de vereadores, que aprovaram o documento da forma como foi apresentado pelo executivo, em sessão plenária realizada em 23 de Junho de 2015 com 14 votos favoráveis, 4 votos contra e uma ausência. Os parlamentares justificaram a aprovação aligeirada pelo fato de não haver prazo para reformulações, visto que o prazo de 01 (um) ano estipulado pelo PNE estava se esgotando, como informa notícia em veículo de comunicação local.

Tal sessão plenária foi realizada diante de centenas de representantes da sociedade, que defendiam a apreciação e votação das ementas apresentadas pelo vereador Elias Ishy, no entanto toda a mobilização social não sensibilizou os parlamentares, que justificaram a necessidade de votação dentro do prazo exigido pelo

${ }^{4}$ Elias Ishy questiona falta de diálogo sobre o Plano Municipal de Educação. http://www.camaradourados.ms.gov.br/imprensa/elias-ishy-questiona-falta-de-dialogo-sobre-o-planomunicipal-de-educacao 


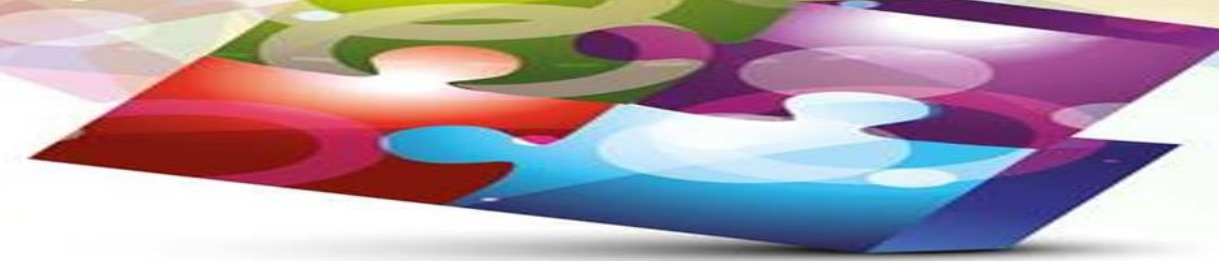

PNE, sob pena de suspensão no repasse dos recursos federais destinados aos municípios.

Esse tipo de postura do legislativo reflete o posicionamento político e social de cada um, conforme defendido por Pinto (2008)

O momento crítico que explica a proeminência de um item na agenda não é a sua fonte, mas o "ambiente" do governo e a receptividade da idéia,aliados à combinação de atores envolvidos na decisão, elaboração e implementação de uma política pública. A chave, portanto, para se entenderas mudanças nas políticas públicas, não está na origem da idéia, mas no entendimento do processo de crescimento dessa idéia (PINTO, 2008, p.31).

O acontecimento gerou insatisfação em parte dos envolvidos no processo de construção do documento, considerado um desrespeito à categoria, que se dedicou e se envolveu no processo com a esperança de garantia de direitos por meio do PME. Indignação e protestos marcaram a assembléia de votação do PME na Câmara Municipal, no entanto, as vozes dos protagonistas não foram ouvidas naquele momento, conforme relato publicado no site do sindicato

Antes da sessão extraordinária na manhã de ontem, os educadores da rede municipal realizaram uma assembléia em frente a Câmara Municipal e depois acompanharam a primeira votação. Na segunda votação, realizada a noite houve protestos por parte dos estudantes universitários da UFGD (Universidade Federal da Grande Dourados) que levaram faixas e cartazes e gritando palavras de ordem. O presidente da casa, vereador Idenor Machado (DEM) desrespeitou o protesto dos estudantes ameaçando retirá-los do plenário caso não parassem com a manifestação (SIMTED, 2015).

Frente ao movimento que ganhou força com o apoio do SIMTED e a exposição que o caso tomou nas manchetes dos jornais locais e mídia eletrônica, os vereadores se sentiram prejudicados moralmente, resultando numa ação judicial movida por parte dos vereadores contra o sindicato. Em resposta a essa ação, o diretor do SIMTED declarou por meio de nota no site da instituição 


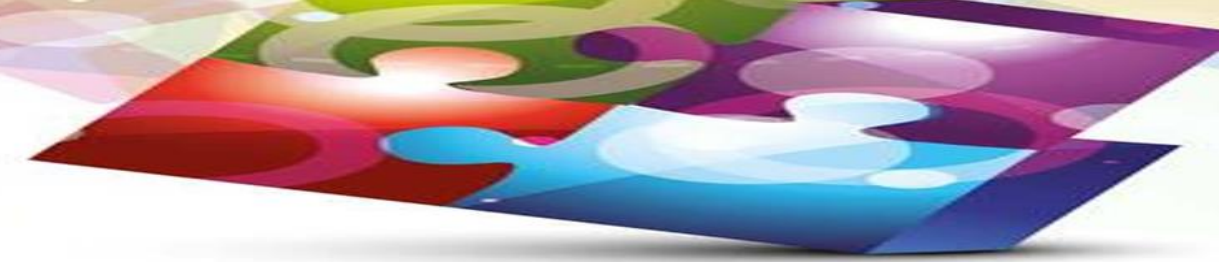

O SIMTED tem tranquilidade em responder esses processos e que assim que estes forem encerrados, iremos nos reunir novamente e tomar futuras providências em defesa da democracia e dos nossos direitos com relação a essa situação (SIMTED, 2015).

Mesmo diante do cenário de embate em torno da construção, formulação e aprovação do PME, o documento aprovado se configura como norteador das políticas municipais de educação a serem executadas nos dez anos subsequentes a sua aprovação.

O projeto de Lei aprovado no dia 23 de Junho de 2015, tornou-se Lei N. 3.904 que "Aprova o Plano Municipal de Educação de Dourados-MS e dá outras providências", com vigência decenal (2015 a 2025) em consonância ao cumprimento do disposto no art. 214 da Constituição Federal, do art.194 da Constituição Estadual, do art. 8. ${ }^{\circ}$ da lei federal n. ${ }^{\circ} 13.005$ (PNE) e a lei estadual N. ${ }^{\circ} 4.621$ (PEE-MS).

O PME Dourados é composto por 20 metas e 301 estratégias, possui as mesmas metas do Plano Nacional de Educação (PNE 2014-2024), contendo suas especificidades nas estratégias.

Deste modo, a educação pública municipal é regida atualmente e nos próximos anos por este documento, cabe agora cobrar para que as estratégias sejam cumpridas. Sobre isso o Artigo 3..$^{\circ}$ do PME estabelece

As metas e estratégias previstas no anexo desta Lei serão objeto de monitoramento contínuo e de avaliações periódicas, realizados pela Comissão Municipal de Monitoramento e Avaliação do PME (CMMA), que será instituída e nomeada pelo chefe do Poder Executivo, com a participação das seguintes instâncias:

I-Secretaria Municipal de Educação (SEMED);

II-Secretaria de Estado de Educação (SED);

III-Comissão de Educação da Câmara Municipal;

IV- Conselho Municipal de Educação (COMED);

V-Fórum Municipal de Educação (FME);

VI-Ministério Público - Promotoria da Infância e Juventude;

VII-Sindicato Municipal dos Trabalhadores em Educação (SIMTED);

VIII-Associação de Pais e Mestres (APms);

IX-Universidades (DOURADOS, 2015, p.15).

Sobre a comissão de acompanhamento do PME, o Fórum Municipal de Educação (FME) do município de Dourados se configura como uma das instâncias 
necessárias para o monitoramento das Metas do PME. O FME foi instituído pelo Decreto N. ${ }^{\circ} 551^{5}$ de 12 de setembro de 2017 e tem como função servir de

[...] órgão de consulta, assessoramento e de deliberação de propostas para políticas educacionais. É constituído de forma colegiada por representantes da sociedade civil organizada, órgãos públicos, movimentos sociais e segmentos da comunidade educacional (DOURADOS, 2019).

A Lei N. 3.904 (PME/2015) traça estratégias objetivas, considerando o contexto municipal e regional garantindo um melhor desenvolvimento e aplicação prática das estratégias formuladas, se forem cumpridas, com certeza trarão melhorias significativas à educação pública municipal.

\section{Considerações}

Conclui-se com essa pesquisa que, o PME de Dourados foi coordenado pelo governo municipal, tendo início como pauta na agenda das políticas educacionais do município posteriormente a aprovação do PNE (2014). Foram 18 meses de diálogos até a transformação em Lei N. ${ }^{\circ} 3.904$ em 23 de Junho de 2015.

O levantamento realizado no município de Dourados evidencia expressivo comprometimento da ordem democrática no engajamento da sociedade civil seja atuante ou por meio de seus representantes no processo de elaboração do Plano Municipal de Educação de Dourados, o que, no entanto, não impediu as alterações efetuadas por parte do poder executivo na versão final do documento.

Tais alterações, de forma arbitrária, em grande parte suprimindo estratégias que demandavam questões orçamentárias e suprimindo prazos para o cumprimento de algumas estratégias, explicitando nacionalmente, uma vez que o PME está alinhado ao PEE e ao PNE, o descompromisso do executivo e do legislativo municipal com a educação.

\footnotetext{
${ }^{5}$ Conforme informações do site da prefeitura de Dourados, dentre as ações propostas pela coordenação do FME estão, estudos e debates sobre a política municipal de educação, mobilizar a sociedade para a discussão de políticas educacionais, acompanhar a implantação e implementação da legislação específica da educação básica e da educação superior no município, promover a articulação entre os órgãos e segmentos da sociedade civil envolvidos com a educação no município, entre outras.
} 


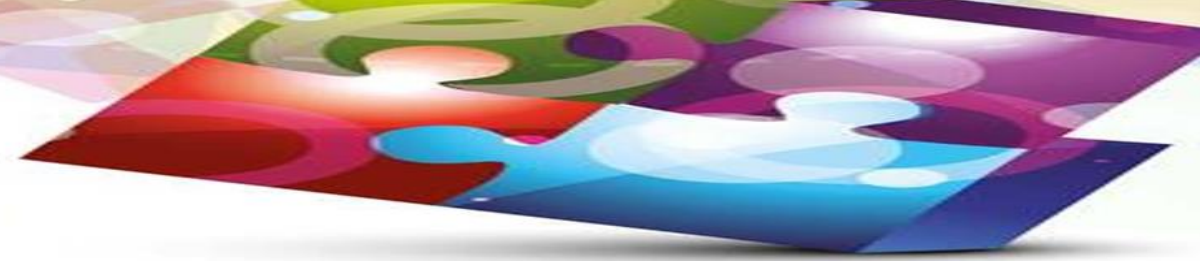

Do executivo porque foi o autor das supressões por meio da ação direta da Procuradoria Geral do Município (PGM) e do legislativo porque o documento foi votado e aprovado na casa de leis, de forma truculenta e autoritária, mesmo diante de manifestação ativa da categoria de educadores do município de Dourados.

Logicamente, que numa percepção crítica dada pela pesquisa, registra-se que muitos empecilhos são encontrados quando se busca fazer de fato a democracia almejada, não podendo deixar de lado a análise de que um deles está na infraestrutura da sociedade capitalista.

Dessa forma, fica evidente que a formulação de documentos legais, expressa a maneira mais cabível de expor as necessidades e interesses diante da realidade da comunidade escolar, bem como, uma forma de garantir, legalmente, o cumprimento e obrigatoriedade por parte do poder executivo de efetivar determinadas ações.

Embora a aprovação da Lei N. ${ }^{0} 3.904$ não evidenciou satisfatoriamente todos os anseios depositados pelos educadores, alunos e sociedade civil organizada, o debate em torno das políticas públicas educacionais trouxe avanços significativos para o município de Dourados.

As plenárias de elaboração das estratégias do PME serviram como um terreno fértil de idéias, diálogos, propostas, debates e embates que teve como protagonista a comunidade escolar unida em um único propósito: melhoria da qualidade da educação municipal.

Registra-se que, é inegável que ainda consiste em interesses políticos, interesses esses que na maioria das vezes, se sobressaem em relação ao compromisso com uma melhoria na qualidade do ensino.

Percebe-se que aspectos em relação à políticas educacionais contemplados na legislação educacional brasileira vigente, ainda são precoces no que diz respeito à concretização e efetivação de políticas eficientes no combate à superação das desigualdades políticas, econômicas, culturais e sociais.

Em suma, ressalta-se que a relevância social e educacional do estudo feito está na oportunidade de compreender que a qualidade da educação por meio de uma 


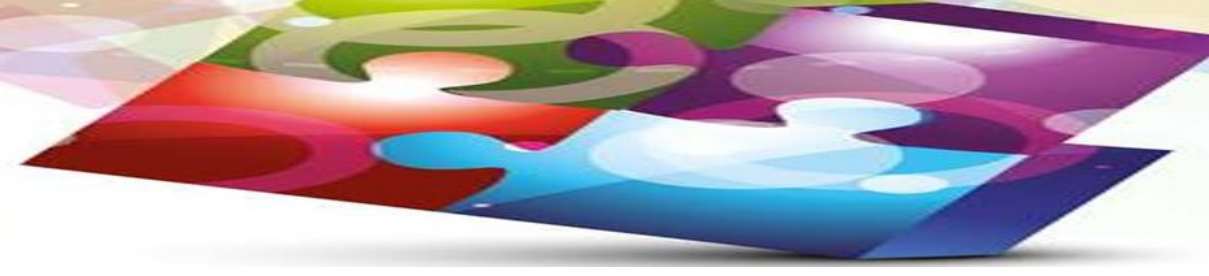

educação pública de qualidade social deve estar pautada numa política de Estado, independente da concepção política do governo local.

Cabe a comunidade escolar por meio de seus representantes buscar e lutar por questões que estão além da sala de aula, lutar por espaços nas esferas políticas, que também fazem parte do processo educacional e que tem estreita ligação com a qualidade educacional e com a gestão democrática da educação.

\section{Referências}

BRASIL. Lei No 13.005 de 25 de Junho de 2014 . Plano Nacional de Educação. Disponível em: <http://pne.mec.gov.br/conhecendo-o-pne>. Acesso em: 26 fev.2017.

BRASIL. Ministério da educação. Planejando a próxima década. Brasília, DF.2014. Disponível em: http://pne.mec.gov.br/images/pdf/pne_conhecendo_20_metas.pdf. Acesso em: 15 jan. 2017.

CURY, Carlos Roberto Jamil. Planos Nacionais de Educação no Brasil. In: FERREIRA, Eliza Bartolozzi; FONSECA, Marília. (Orgs.) Política e Planejamento educacional no Brasil do século 21. Brasília: Liber Livro, 2013. p.25-34.

DOURADOS. Lei $\mathbf{N}^{\mathbf{0}} \mathbf{3 . 9 0 4}$ de 23 de Junho de 2015. Plano Municipal de Educação. Disponivel em : <http://www.dourados.ms.gov.br/wp-content/uploads/2015/07/Lein\%C2\%BA-3904-PME-Dourados-MS.pdf. > Acesso em: 20 out.2016.

DOURADOS. Prefeitura Municipal de Dourados (Site oficial). Disponível em: <http://www.dourados.ms.gov.br/index.php/plano-municipal-de-educacao-e-finalizadoem-dourados/> Acesso em: 05 maio 2016.

DOURADOS. Prefeitura Municipal de Dourados (Site oficial). Disponível em: http://www.dourados.ms.gov.br/index.php/forum-municipal-de-educacao-dedourados-e-dia-14-de-marco/. Acesso em 14 jun.2019.

GODOY, Arlinda Schimidt. Introdução à pesquisa qualitativa e suas possibilidades. RAE - Revista de Administração de Empresas, São Paulo, v. 35, n. 2, p. 57-63, 1995. Disponível em: < http://www.scielo.br/scielo.php?script=sci_arttext\&pid=S0034$75901995000200008>$. Acesso em: 19 ago. 2017.

IBGE. Sistema IBGE de Recuperação Automática - SIDRA. Disponível: site. http://www.sidra.gov.br/bda/tabela/listabl.asp. Acesso em 17 maio 2016. 


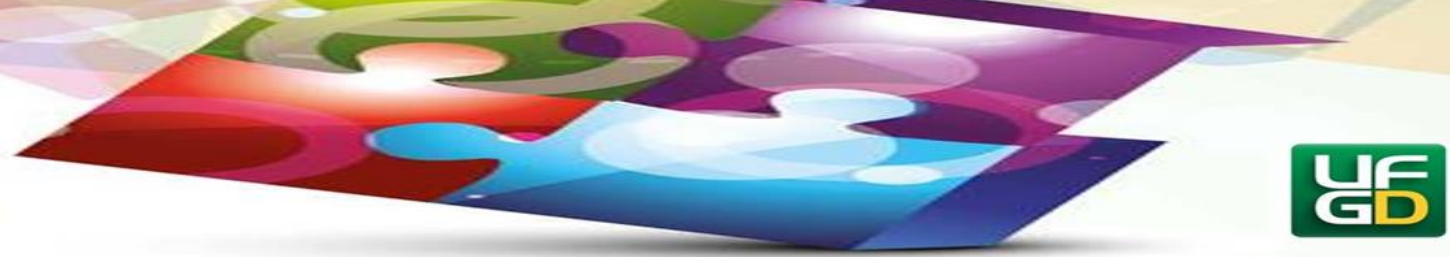

PALUMBO, Dennis J. A abordagem de política pública para o desenvolvimento político na América. In: Política de capacitação dos profissionais da educação. Belo Horizonte: FAE/IRHJP, 1994.p. 35-61.

PINTO, Isabela Cardoso de Matos. Mudanças nas Políticas Públicas: a perspectiva do ciclo de política. Rev. Pol. Públ. São Luis, v. 12, n. 1, p. 27-36, jan./jun. 2008.

SHIROMA, Eneida Oto; CAMPOS, Roselane Fátima; GARCIA, Rosalba Maria Cardoso. Decifrar textos para compreender a política: subsídios teórico-metodológicos para análise de documentos. Revista Perspectiva, Florianópolis, v. 23, n. 02, p. 427446, jul./dez. 2005.

SIMTED. Site Oficial Sindicato Municipal dos Trabalhadores em Educação de Dourados. Disponível em: http://www.simted.org.br/noticias/secretaria-municipal-deeducacao-realiza-seminario-livre-sobre-plano-de-educacao. Acesso em: 22 fev. 2016.

SOUZA, Aécio Candido de. Educação profissional e cidadã: integração à sociedade. In: Sistema Nacional de Educação e o PNE. Magna França (org). Brasília:Liber Livro,2009. UFRN. p.223-256.

Data do envio do trabalho: 02/07/2019

Aprovado em: 18/11/2019

Publicado em: 18/12/2019 